\section{Commentary: Minimally invasive esophagectomy-practice what you preach}

\author{
Jordan A. Wilkerson, MD, and \\ DuyKhanh P. Ceppa, MD
}

Esophagectomy remains a key component in the treatment of esophageal cancer despite its notorious association with high morbidity. Minimally invasive approaches have emerged over the last several decades as a safe alternative without compromised oncologic outcomes compared with open esophagectomy. Moreover, newer studies have shown improved perioperative morbidity for both totally minimally invasive esophagectomy (MIE) and hybrid approaches. ${ }^{1,2}$ This suggests that a minimally invasive technique should be the favored approach when feasible and for appropriately selected patients. However, survey data have illustrated a lack of confidence in minimally invasive techniques among recent graduating cardiothoracic surgery residents secondary to limited exposure to such techniques during their training. ${ }^{3}$

In this issue, Drs Taylor and Maloney examine national trends in the use of MIE or hybrid esophagectomy in their retrospective analysis of more than 26,000 esophagectomies performed in the United States between 2016 and 2018. ${ }^{4}$ Although they present their results in a rather simplified manner, the overall message is a steady increase over time in the percentage of minimally invasive esophagectomies being performed across all institutions. However, the authors report that a higher percentage of minimally

\footnotetext{
From the Division of Cardiothoracic Surgery, Department of Surgery, Indiana University School of Medicine, Indianapolis, Ind.

Disclosures: Dr Ceppa serves on an advisory board for Astra Zeneca and as a consultant for Medtronic. Dr Wilkerson reported no conflicts of interest.

The Journal policy requires editors and reviewers to disclose conflicts of interest and to decline handling or reviewing manuscripts for which they may have a conflict of interest. The editors and reviewers of this article have no conflicts of interest.

Received for publication Nov 2, 2020; revisions received Nov 2, 2020; accepted for publication Nov 6, 2020; available ahead of print Dec 3, 2020.

Address for reprints: DuyKhanh P. Ceppa, MD, Department of Surgery, Indiana University School of Medicine, 545 Barnhill Dr, EH 215, Indianapolis, IN 46202 (E-mail: dpceppa@iupui.edu).

JTCVS Open 2021;5:195-6

2666-2736

Published by Elsevier Inc. on behalf of The American Association for Thoracic Surgery. This is an open access article under the CC BY-NC-ND license (http:// creativecommons.org/licenses/by-nc-nd/4.0/).

https://doi.org/10.1016/j.xjon.2020.11.002
}

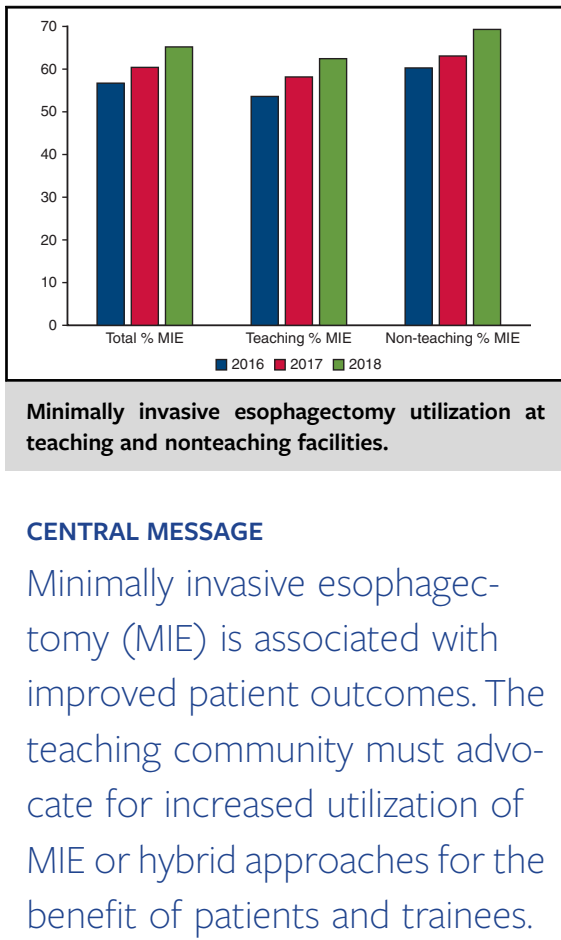

invasive surgeries are performed at nonteaching centers compared with teaching hospitals for both transhiatal and transthoracic approaches, and that this difference has persisted over time. These findings are important, highlighting an area for potential improvement in cardiothoracic surgery residency training, even though the data suggest that operative exposure to MIE is already trending in a favorable direction.

The discrepancy in minimally invasive surgery identified between nonteaching and teaching institutions is likely multi-factorial in etiology. The treatment of more advanced disease tends to be centralized to high-volume teaching centers, resulting in a higher proportion of patients who might not be amenable to MIE at teaching institutions. In addition, there are significant constraints on teaching institutions, in which emphasis on patient outcomes and operative time must be balanced with resident education. Nevertheless, it is disappointing to see teaching institutions lagging behind in the adoption of MIE and hybrid approaches, given that they are the primary source of studies demonstrating improved outcomes compared with open esophagectomy in terms pf perioperative morbidity. Limited utilization of MIE may have repercussions on propagating MIE techniques among trainees, as the likelihood of incorporating MIE into practice is related to overall exposure. 
In conclusion, it is apparent that we must continue to strive for increased utilization of minimally invasive approaches in the management of esophageal cancer to provide improved outcomes for patients while simultaneously benefitting resident education. Increased exposure is needed to promote confidence among trainees on graduation, especially in relation to complex operations that involve such a steep learning curve. Thus, the teaching community must embrace the role of advocate for minimally invasive approaches and further lead by example by demonstrating consistency in what we publish and what we do.

\section{References}

1. Biere SS, van Berge Henegouwen MI, Maas KW, Bonavina L, Rosman C, Garcia JR, et al. Minimally invasive versus open oesophagectomy for patients with oesophageal cancer: a multicentre, open-label, randomised controlled trial. Lancet. 2012;379:1887-92.

2. Mariette C, Markar SR, Dabakyuo-Yonli TS, Meunier B, Pezet D, Collet D, et al. Hybrid minimally invasive esophagectomy for esophageal cancer. $N$ Engl J Med. 2019;380:152-62.

3. Rothenberg PE, Hughes BD, Amirkhosravi F, Onaiwu BP, Okereke IC. Factors during training which predict future use of minimally invasive thoracic surgery. Ann Med Surg. 2018;35:149-52.

4. Taylor LJ, Maloney JD. Crisis of confidence in cardiothoracic trainees: national trends in the use of minimally invasive esophagectomy. J Thorac Cardiovasc Surg Open. 2021;5:193-4. 